\title{
VIGILÂNCIA EM SAÚDE NA ENFERMAGEM: O CASO DAS MEDICAÇÕES SEM PRESCRIÇÃO EM CRIANÇAS
}

Surveillance at health in nursing: the case of medications without prescription in children.

Vigilancia de la salud en enfermería: el caso de los medicamentos sin receta para los niños.

\section{RESUMO}

A automedicação é um hábito comum em nosso país e sempre foi um assunto muito discutido e controverso. Muitas mães recorrem à prática de medicar por conta própria suas crianças quando estas apresentam algum sintoma decorrente ou não de alguma patologia. Esta pesquisa teve como objetivo descrever os motivos que levaram as mães a administrarem medicações sem prescrição profissional a seus filhos. Foram entrevistadas 20 mães de crianças menores de 10 anos cadastradas no programa de Crescimento e Desenvolvimento da Unidade de Saúde da Família do município de Passagem, interior do Rio Grande do Norte. Entre as 20 mães entrevistadas, 30\% automedicaram seus filhos com antipirético, 50\% automedicaram devido à febre, 43\% foram motivadas pela experiência anterior e $90 \%$ não relataram efeitos adversos. A automedicação na população infantil reforça a necessidade de um melhor esclarecimento às mães sobre os riscos da automedicação.

Palavras-chave: Automedicação. Criança. Mães. Enfermagem.

\begin{abstract}
The self-medication is a common habit in our country and has always been very discussed and a controversial subject. Many mothers rely on the practice of medicating their children without medical prescription when they present any symptoms from a disease, even if this disease is not confirmed. This research aims to describe the reasons that led the mothers to administer medications without prescription by professional to their children. 20 mothers of children under 10 years enrolled in the program for Growth and Development of Family Health Facility of Passage city, have been interviewed in the interior of Rio Grande do Norte. Among the 20 mothers interviewed, 30\% gave over-the-counter medications to their children, such as Antipyretic, $50 \%$ self-medicated due to fever, $43 \%$ were motivated by past experience and $90 \%$ reported no adverse effects. The self-medication in the child population points out the need for better information to mothers about the selfmedication risks.
\end{abstract}

Keywords: Self medication. Child. Mothers. Nursing.

\section{Resumen}

La automedicación es una conducta frecuente en nuestro país y siempre ha sido un tema muy cuestionable y polémico. Muchas madres recuren a la práctica de auto-medicar sus niños cuando ellos presentan cualquier síntoma resultante o no de una patología. Esta encuesta objetiva describir los motivos que llevaron las madres a utilizar medicamentos sin prescripción profesional en sus hijos. Se entrevistaron 20 madres de niños menores que diez años registradas en el Programa de Crecimiento y Desarrollo de la Unidad de Salud de la Familia en la ciudad de Passagem, en el estado de Rio Grande do Norte, en Brasil. Entre las 20 madres encuestadas, 30\% automedicaron a sus hijos con Antipirético, 50\% los auto-medicaron debido a la observación de fiebre, $43 \%$ lo hicieron basadas en experiencias previas y $90 \%$ no han relatado efectos adversos. La automedicación entre la población de niños demuestra la necesidad de que mejor se informe a las madres cerca de los peligros de la auto-medicación.

Palabras clave: Automedicación. Niño. Madres. Enfermería

${ }^{1}$ Enfermeira, Especialista em Saúde da Criança pela Universidade Federal do Rio Grande do Norte - UFRN. Natal-RN. Brasil. E-mail: rearamed@hotmail.com, ${ }^{2}$ Enfermeira, Especialista em Saúde da Criança pela Universidade Federal do Rio Grande do Norte-UFRN. Natal-RN. Brasil. E-mail: vioskabezerra@bol.com.br, ${ }^{3}$ Doutora, Professora do Departamento de Enfermagem da Universidade Federal do Rio Grande do Norte - UFRN. Natal-RN. Brasil. E-mail: sorayamaria@digi.com.br 


\section{INTRODUÇ̃̃O}

A automedicação é um hábito comum em nosso país e sempre foi um assunto muito discutido e controverso. Ela é definida como uma forma comum de autoatenção à saúde através do consumo de um produto com o objetivo de tratar ou aliviar sintomas ou doenças percebidas, ou mesmo de promover a saúde, independente da prescrição profissional. ${ }^{1}$

É um fenômeno potencialmente nocivo à saúde, pois nenhum medicamento é inócuo ao organismo. ${ }^{2} 0$ uso indevido de substâncias e até mesmo de drogas consideradas comuns pela população pode acarretar diversas consequências, como resistência bacteriana, reações de hipersensibilidade, dependência e sangramento digestivo, e ainda aumentar o risco para determinadas neoplasias. Além disso, o alívio momentâneo dos sintomas encobre a doença de base que passa despercebida e pode, assim, progredir. ${ }^{1}$

Estudos sobre a automedicação no Brasil apresentam dados conflitantes na estatística de prevalência, haja vista que seus valores variam de $42,1 \% 3$ a $83 \%{ }^{4}$

No Brasil, onde a maioria da população possui escassa instrução e informação com relação a medicamentos e seu uso correto, a prática da automedicação torna-se arriscada. ${ }^{2}$ Além disso, não há formas de controle rígidas estipuladas por agências reguladoras e o envolvimento de profissionais da área da saúde é insuficiente. Some-se a isso a falta de orientação dos usuários e da obrigatoriedade da apresentação de receita médica na compra de medicamentos. ${ }^{2}$

Infelizmente, como ocorre com a população, em geral, muitas mães também recorrem à prática de medicar por conta própria suas crianças quando estas apresentam algum sintoma desagradável, decorrente ou não de alguma patologia, de acordo com evidências científicas.

Em um estudo realizado sobre a automedicação com crianças na faixa etária variando entre 2 anos e 11 meses e 4 anos e 4 meses apontou-se uma prevalência de 55,8\% de consumo de medicamentos sem prescrição médica, por influência das mães. ${ }^{5}$

As causas para sua existência são inúmeras; dentre tantas se pode facilmente citar a grande impossibilidade de uma boa parte das pessoas terem acesso ao atendimento médico ou odontológico, seja por questões financeiras ou por próprio hábito de tentar solucionar os problemas de saúde corriqueiros tomando por base a opinião de um conhecido mais próximo. Também o cenário familiar é contexto de construção de práticas culturais, de modo de olhar e de agir engendrado em uma intricada rede de símbolos e significados. ${ }^{6}$ Além disso, a frequente repetição de propagandas através da mídia eletrônica é muitas vezes um fator contribuinte e decisivo para o uso de medicamentos sem prescrição profissional de forma indiscriminada por parte das mães.
Como os medicamentos são definidos como produtos para a saúde com finalidades profilática, curativa, paliativa ou diagnóstica, deverão atender a uma série de requisitos para a sua produção, distribuição, comércio e uso. Para tanto é necessário ser instituído no país um sistema efetivo de vigilância de medicamentos que venha controlar todas essas etapas, a fim de garantir a qualidade, a eficácia, a segurança e o uso racional desse produto.

Neste contexto como define a Lei Orgânica da Saúde (Lei 8.080/90), a Vigilância Sanitária é o conjunto de atividades que permite reunir a informação indispensável para conhecer, a qualquer momento, o comportamento de indicadores da saúde, bem como detectar ou prever alterações de seus fatores condicionantes.?

Desta forma, a partir de 1992, a Vigilância Sanitária avançou no processo do controle da qualidade do medicamento consumido no país, implantando novos regulamentos com o objetivo de assegurar um melhor controle, intensificando a avaliação dos processos de produção dos medicamentos. Além disso, a Vigilância Sanitária estendeu esse monitoramento a outras etapas da cadeia do medicamento, como a dispensação e o consumo de medicamentos pela população. ${ }^{?}$

A Vigilância Sanitária é subdividida em três esferas principais: Nacional - Agência Nacional de Vigilância Sanitária (Anvisa), Estadual - Coordenadoria em Vigilância Sanitária (Covisa) e Municipal - Subcoordenadoria de Vigilância Sanitária (Suvisa), todas seguindo as mesmas diretrizes, contudo com âmbitos de atuação diferentes. ${ }^{7}$

Neste sistema de operacionalização é que são elaboradas estratégias para o uso racional dos medicamentos, entre os quais a dispensação de medicamentos por estabelecimentos autorizados que assegure ao consumidor a disponibilidade oportuna dos medicamentos que realmente necessita e que não seja induzido ao uso indiscriminado e irracional dos mesmos. ${ }^{7}$ Isso porque a automedicação pode trazer sérias consequências para o indivíduo, tais como mascaramento de doenças evolutivas, enfermidades iatrogênicas e diversos efeitos indesejáveis, principalmente quando se trata de crianças. Neste sentido, a automedicação deve ser vista como um problema de Saúde Pública.

Sendo a automedicação um problema comum no Brasil, são necessários estudos sobre o assunto com o intuito de esclarecer à população quais os riscos que o consumo abusivo de medicamentos sem prescrição pode causar em crianças.

Portanto, a presente pesquisa teve como objetivo descrever os motivos que levaram as mães a administrarem medicações sem prescrição profissional a seus filhos. Desta forma poderá contribuir como referencial teórico existente sobre a temática e, mais especificamente, sobre a realidade pouco conhecida da temática na região Nordeste. 


\section{MÉTODO}

0 presente trabalho é um estudo do tipo descritivo, exploratório com abordagem qualitativa.

0 cenário da pesquisa foi a Unidade de Saúde da Família do município de Passagem, localizado na região Agreste do estado do Rio Grande do Norte/RN, com população existente de 2.629 habitantes. ${ }^{8}$ Participaram da pesquisa 20 mães de crianças menores de 6 anos do total de 60 cadastradas no Programa de Crescimento e Desenvolvimento (CD), o qual faz parte da avaliação integral à saúde da criança de 0 a 6 anos, realizada periodicamente conforme a idade, no referido município. Estas foram entrevistadas e incluídas na pesquisa quando compareceram à Unidade no período de pesquisa de campo (setembro a dezembro de 2007), aceitaram participar livremente da pesquisa ao serem informadas sobre o seu propósito e assinaram o termo de consentimento livre esclarecido. Os critérios de exclusão foram o não comparecimento da mãe na Unidade no período da pesquisa de campo e a recusa em participar da pesquisa.

0 roteiro de entrevista constou de uma caracterização das entrevistadas, através do preenchimento de um formulário no qual foi coletada idade, nível de escolaridade e profissão da mãe, idade e sexo da criança, renda familiar média, estado civil e prática religiosa. 0 mesmo continha também questões abertas a partir de perguntas geradoras, enfocando o uso, motivos e conhecimentos da mãe sobre a medicação utilizada sem orientação profissional.

A análise das informações foi realizada por sistematização das falas, através das convergências e divergências das respostas encontradas nos roteiros de entrevistas e definidas em categorias que emergiram do processo de investigação. As categorias foram: (1) medicação sem prescrição versus sintomatologia da criança; (2) efeitos adversos e (3) medicação versus Unidade de Saúde.

Todos os aspectos éticos foram considerados durante o processo da pesquisa, respeitando os princípios da Resolução 196/96 do Conselho Nacional de Saúde. 0 estudo e seu consentimento informado foram submetidos e aprovados pelo Comitê de Ética da Universidade Federal do Rio Grande do Norte através do protocolo número 088/07.

\section{RESULTADOS E DISCUSSÕES}

Neste item serão abordados os resultados e as discussões da presente pesquisa, enfocando a análise a partir das categorias estabelecidas.

\section{Medicamento sem prescrição versus sintomatologia da criança}

Dentre as mães entrevistadas que automedicaram os seus filhos nos últimos três meses, os medicamentos mais utilizados foram: Paracetamol $-30 \%$, Vitamina C $-20 \%$, Dipirona-20\%, Xarope - $20 \%$ e Amoxicilina - $10 \%$.
Em relação ao tipo de medicamento mais consumido, foram encontradas duas linhas distintas na literatura: uma delas relata o uso de antibióticos como o grupo farmacológico mais utilizado, ${ }^{9}$ seguido pelos analgésicos. No entanto, existem pesquisas que destacam os analgésicos/antipiréticos ${ }^{2,10}$ como medicamentos mais utilizados na automedicação, associandoa ao tratamento sintomático.

Quanto à predominância dos analgésicos entre os medicamentos mais procurados, esse é um fato comum tanto na automedicação praticada no Brasil como em outros países. ${ }^{2,4-5}$

Outro aspecto relevante correlaciona-se ao uso de antibióticos na prática da automedicação. Em um estudo ${ }^{11}$ realizado em Fortaleza (CE), a automedicação por uso de antibiótico apresentou uma prevalência de 37\%. Sabe-se que a prescrição de antimicrobianos é indispensavelmente feita a partir do antibiograma, exame que prediz a sensibilidade da bactéria envolvida no processo infeccioso aos antimicrobianos. 0 uso indevido de antimicrobianos e o tratamento incompleto poderão ocasionar diversos problemas, entre os quais a resistência bacteriana, que pode resultar em uma posterior utilização de antimicrobianos de reserva em infecções bacterianas mais simples, o que acarreta um aumento no custo do tratamento. ${ }^{12}$

No presente estudo, o único antibiótico utilizado pelas entrevistadas foi a amoxicilina. Esta pertence ao grupo dos antibióticos penicilânicos e é usada para o tratamento de uma gama de infecções causadas por bactérias, como infecções no peito (pneumonia), amígdalas (amigdalite), seios da face (sinusite), trato urinário e genital, pele e mucosas. ${ }^{12}$

\section{Efeitos Adversos}

Os mais variados efeitos adversos podem surgir do uso racional e irracional dos medicamentos. Entre os efeitos adversos ocasionados pela utilização da amoxicilina, pode-se citar: diarreia, indigestão, sensação de mal-estar, aftas na língua ou na boca, prurido, erupções na pele, hematomas ou sangramentos anormais, pele ou olhos amarelados e urina escura ou fezes esbranquiçadas. ${ }^{12}$

Com relação às doenças que as mães entrevistadas acreditavam que seus filhos tinham e que justificaram a automedicação por elas, foi verificado o seguinte: em primeiro lugar foi citada febre (50\%), seguida por gripe (25\%), resfriado (13\%) e infecção na garganta (12\%).

De maneira geral, os sinais e sintomas das doenças citadas anteriormente são menores e característicos de doenças autolimitadas, de remissão espontânea e ou afecções cíclicas, o que condiz com a literatura consultada. ${ }^{4}$, 13-14 Desta forma, o uso dos analgésicos, vitaminas e preparados para tosse são justificados, mas o uso da amoxicilina não, haja vista que está indicada no tratamento de doenças e condições crônicas. ${ }^{12}$

Os principais motivos que geraram a automedicação foram febre (43\%), experiência anterior (43\%) e gripe (14\%). 
Em um estudo realizado com pacientes otorrinolaringológicos, verificou-se que as cefaléeas (76\%), seguidas por resfriados e gripes (74\%) e quadros febris (56\%), foram os motivos ou doenças que os pacientes acreditavam ter que justificaram a automedicação. ${ }^{4}$

A experiência anterior como um dos motivos relacionados à automedicação é um fato bastante significativo, pois o tratamento correto de doenças que acarretam em restabelecimento da saúde estimula as pessoas a reproduzi-lo para si e para os outros. ${ }^{15}$

Em relação aos efeitos colaterais/efeitos adversos, $90 \%$ das mães relataram ausência destes, enquanto $10 \%$ não responderam à pergunta.

A alta prevalência de ausência de efeitos adversos pode estar relacionada ao medo das mães de assumirem a culpa por terem causado mal aos seus filhos com a automedicação ou por pura ignorância. ${ }^{2,5}$ Quando o erro ocorre, a tendência é escondê-lo, perdendo-se oportunidade importante de aprendizado. ${ }^{16}$ Levando-se em consideração os efeitos adversos dos medicamentos mais consumidos, como tonturas, náuseas, febre alta e sensação de frio, a mãe pode confundi-los simplesmente com sinais e sintomas das doenças que mais levaram à automedicação, como a gripe ou o resfriado.

\section{Medicação versus Unidade de Saúde}

A Constituição Brasileira de 1988 representou uma mudança importante para o sistema de saúde com a criação do Sistema Único de Saúde - SUS, reconhecendo a saúde como direito social universal e de cidadania, rompendo com uma longa tradição que vinculava o direito a assistência médica aos trabalhadores com carteira assinada e aos contribuintes da previdência social. O SUS significou a incorporação definitiva de amplas camadas da população brasileira excluídas do direito à saúde. Neste sentido, avançou ao garantir o acesso universal e igualitário aos serviços - "a saúde é direito de todos e dever do estado". 17

As condições de acesso - ou a acessibilidade - referemse ao grau de facilidade ou dificuldade com que os indivíduos se deparam no momento em que buscam obter a atenção médica ofertada pelos serviços de saúde. Estas condições podem ser provenientes de vários fatores, tais como a localização dos serviços, o grau de adequação qualitativa entre oferta e demanda, os procedimentos e requisitos necessários à admissão do paciente ou o tempo de espera que antecede ao atendimento. ${ }^{18}$

Sendo assim, as dificuldades nas condições de acesso podem justificar a prevalência de $30 \%$ na automedicação praticada pelas mães, nos últimos três meses que antecederam as entrevistas.

A dificuldade de acesso ao médico na Unidade de Saúde constitui um fator predisponente à automedicação; contudo, no presente trabalho, não se pode afirmar relação direta entre dificuldade de acesso e automedicação.
As condições de acesso não se limitam à relação quantitativa entre a oferta e a demanda, embora esse seja um dos seus aspectos centrais. Fatores geográficos, organizacionais, financeiros e culturais compõem o mosaico a partir do qual se deve compreendê-las.

\section{CONCLUSÃO}

Dentre as mães entrevistadas que automedicaram seus filhos, $30 \%$ utilizaram paracetamol, $50 \%$ relataram ser febre o sintoma que as levou a administrar um medicamento sem prescrição profissional a seu filho e $43 \%$ alegaram experiência anterior ou febre como motivo para automedicação.

Os dados do presente trabalho confirmam a importância de estudos sobre a automedicação e apoiam a excessiva crença da população no poder dos medicamentos, 0 que contribui para a crescente demanda de produtos farmacêuticos para qualquer tipo de transtorno da saúde, por mais limitado que este seja.

Soma-se a este fato a dificuldade de acessibilidade aos serviços de saúde e a elevação dos custos dos medicamentos, o que contribui para o aumento da crise do Sistema Único de Saúde, fazendo com que aumente também a procura por formas alternativas de medicação, tendo como fim a automedicação.

Neste cenário, o medicamento insere-se na dinâmica do cotidiano da sociedade contemporânea de consumo e para isto está sujeito às mesmas regras de competição de qualquer setor do mercado de vendas. A propagação nos veículos de comunicação, que em sua maioria, somente relata uma situação demonstrativa da eficácia simbólica do medicamento corrobora tal fato, fazendo com que o medicamento fique afastado da sua razão de existência que é o de prevenir sinais/sintomas e tratar enfermidades.

Os resultados do presente trabalho reforçam a necessidade de informar a população sobre o uso adequado de medicamentos, como também a cobrança de medidas cabíveis aos órgãos responsáveis que garantam a oferta de produtos e serviços adequados.

É necessária a construção de uma nova cultura no referente ao uso adequado dos medicamentos, centrada no estudo sistemático dos impactos biológicos (haja vista a falta de monitorização de reações adversas) e sociais. Este é um dos caminhos para o uso racional dos medicamentos, ou seja, a utilização deles apenas como ferramenta essencial na melhora ou prevenção de sinais e sintomas da população.

Além dessa pesquisa, inúmeras outras medidas se fazem necessárias, entre as quais: uma política mais eficaz no controle das propagandas de medicamentos nos veículos de comunicação; trabalhos de sensibilização sobre a automedicação direcionados para a população em geral, bem como para os profissionais da saúde e, no contexto deste trabalho, aos profissionais que trabalham com o programa de 
Crescimento e Desenvolvimento; fiscalizações constantes nos estabelecimentos de venda de medicamentos; veiculação da mídia sobre os riscos da automedicação, entre outras medidas.

0 papel da família, dos profissionais da saúde (médicos, farmacêuticos e enfermeiros) e gestores de saúde é imprescindível para implementar medidas que possam equacionar esse grave problema de saúde pública. Ações de mudança e de transformação de comportamento através de campanhas educativas tornam todos os segmentos da sociedade responsáveis pelo processo de racionalização do uso do medicamento.

\section{REFERÊNCIAS}

1. Paulo LG, Zanini AC. Automedicação no Brasil. Rev Assoc Med Bras. 1988; 34: 69-75.

2. Arrais P, Coelho HLL, Batista MCDS, et al. Perfil da automedicação no Brasil. Rev Saude Publica. 1997 fev; 31(1): 71-77.

3. Simões MJS, Farache Filho A. Consumo de medicamentos em região do Estado de São Paulo (Brasil), 1985. Rev Saude Publica. 1988; 22: 49499.

4. Servidoni AB, Coelho L, Navarro ML, de Avila FG, Mezzalira R. Perfil da automedicação nos pacientes otorrinolaringológicos. Rev Bras Otorrinolaringol. 2006 jan/fev;72:83-8.

5. Béria JU, Victoria CG, Barros FC, et al. Epidemiologia do consumo de medicamentos em crianças de centro urbano da região Sul do Brasil. Rev Saude Publica. 1993 fev; 25(2): 95-104.

6. Roehrs H, Lenardt MH. Práticas culturais familiares e o uso de drogas psicoativas pelos adolescentes: reflexão teórica. Esc Anna Nery. 2008 jun; 12(2): 353-57.

7. Agência Nacional de Vigilância Sanitária-ANVISA. Informação em vigilância sanitária [citado 2008 ago] Disponível em: www.anvisa.gov.br/.

8. Instituto Brasileiro de Geografia e Estatística- IBGE. Censo Demográfico 2007. [citado 2008 ago].Disponível em: http://www.ibge.gov.br/.

9. Haak H. Padrões de consumo de medicamentos em dois povoados da Bahia (Brasil). Rev Saude Publica. 1989; 23: 143-51.

10. Pereira FSVT, Bucaretchi F,Stephan C, Cordeiro R. Automedicação em crianças e adolescentes. Rev Saude Publica. 2007 set; 83(5): 150-58.

11. Menezes EA, Oliveira MS, Cunha FA, Pinheiro FG. Automedicação com antimicrobiano para o tratamento de infecção urinária em estabelecimento farmacêutico de Fortaleza. Infarma.2004; 16 (11): 56-59.

12. Rang HP, Dale MM. Farmacologia. Rio de Janeiro: Guanabara Koogan; 1997.
13. Vilarino JF. Perfil da automedicação em município do Sul do Brasil, Brasil. Rev Saude Publica. 1998; 32: 43-49.

14. Loyola Filho Al, Uchoa E, Firmo JOA, et al. Estudo de base populacional sobre o consumo de medicamentos entre idosos: Projeto Bambuí. Cad Saude Publica. 2005 mar/abr; 21(2): 545-53.

15. Gerstner AP, Kampf CE, Tritinaglia G, et al. Automedicação em Caxias do Sul. Rev Cient AMECS.1993; 2(1): 9-11.

16. Melo ABR, Silva LD. Segurança na terapia medicamentosa. Esc Anna Nery. 2008 mar; 12(1): 166-72.

17. Teixeira C, Paim JS, Vilasboas AL. SUS, modelos assistenciais e vigilância da saúde. In: Teixeira C, organizador. Promoção e vigilância da saúde. Salvador: Instituto de Saúde Coletiva; 2002. P. 23-57.

18. Teixeira CM. A mudança do modelo de atenção à saúde no SUS: desatando nós, criando laços. Saúde em Debate. 2003; 27(65): 257-77. 